\title{
THE EUROPEAN SCIENCE FOUNDATION; DEATH OR MID-LIFE CRISIS?
}

॥ Martin Hynes - Chief Executive - The European Science Foundation - Strasbourg, France - DOI: 10.1051/epn/2015104

It was a $40^{\text {th }}$ birthday party with a difference [1]: to celebrate a lively and eventful past (Figs. 1, 2), but with no clearly-defined future. However, what might have been a wistful event turned into a surprisingly lively one. It applauded the achievement of researchers and the great benefits of European collaboration in science. A commemorative booklet was published for the event and a number of associated events held. Highlights from the past were celebrated; but what does the future hold?

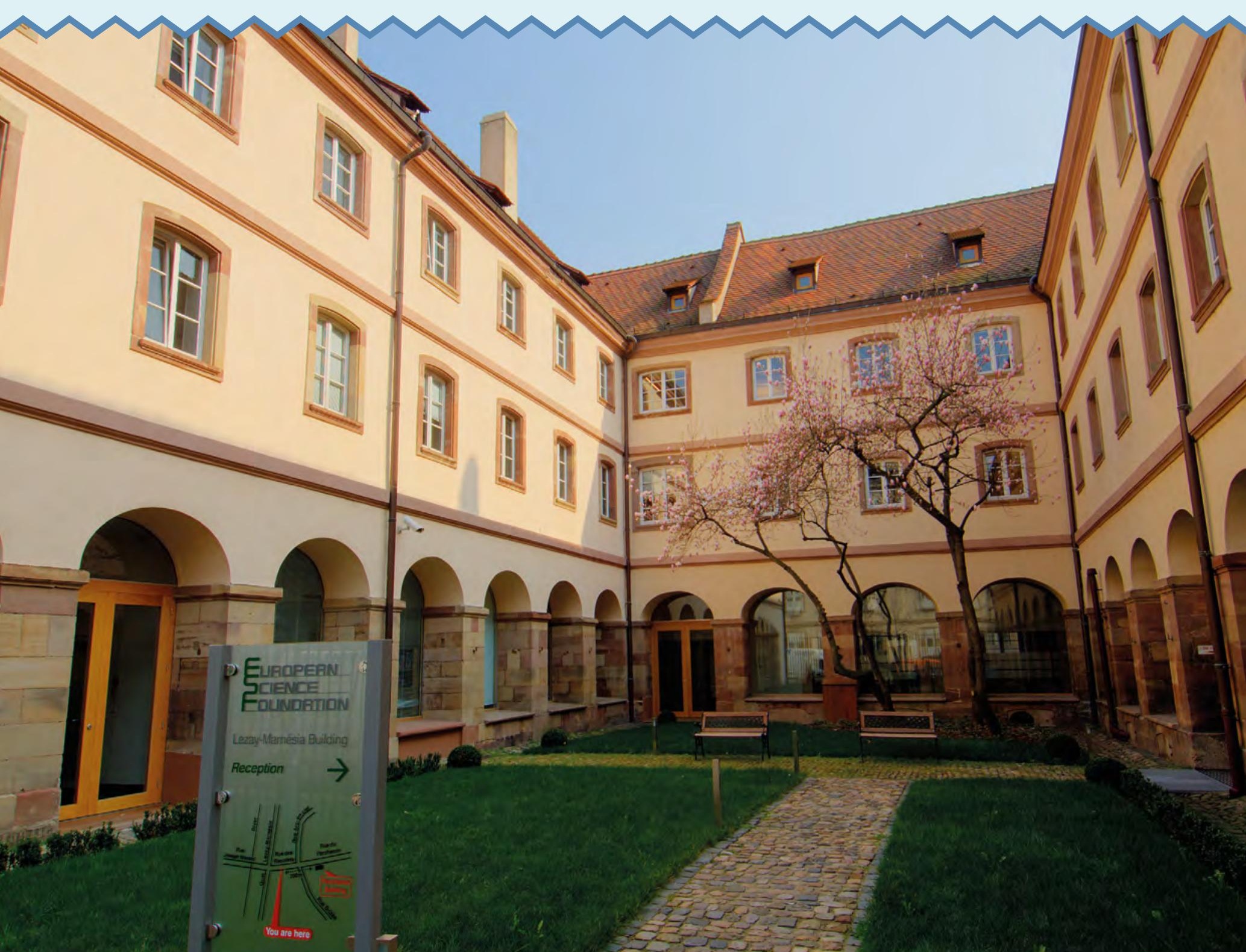


v FIG. 1: ESF Chief Executive, Mr. Martin Hynes and President, Professor Pär Omling, during the $40^{\text {th }}$ anniversary celebrations in Strasbourg, May 15-16, 2014.
W ith 40 years' experience in all areas of research, the European Science Foundation (ESF) was originally set up to act as a coordinating body for Europe's main research funding and research performing organisations. But as the research landscape evolved, so did ESF's role in supporting scientific endeavours.

Some members began to express frustration that the organisation had grown too large and distant from its original mission. At a time of national financial crisis in most countries, members wishing to downsize their international payments considered the future of the association. Indeed, when a vote was held in May 2011, the result was very close to a formal decision to dissolve the organisation directly.

At the same time, some European Heads of Research Councils (EuroHORCS) and ESF members decided to establish a separate body in Brussels with the mission to act as the policy body for elaboration of common positions. The resulting Science Europe was designed to be slim and agile, supported by strong Scientific Committees [2] and acting primarily in a policy role; the intention was to not reproduce the funding instruments and tools of ESF.

Developing this focus, members decided that the combined budget for both ESF and Science Europe should not exceed the peak of funding allocated in the 2011 general budget for ESF alone. Clearly, this implied a strong downward trajectory on ESF financial resources - a reduction of Euro 15.4 Million in member contributions for 2015 compared to 2010 (Fig. 3).

Adapting to these budget cuts, and in accordance with the members' wishes, ESF is winding down its traditional networking activities to reach completion by the end of 2015. Its policy activities have been transferred to Science Europe, and staff numbers dramatically reduced.

However, ESF has the experience and agility to develop solutions and services to face challenges and turn them into opportunities.

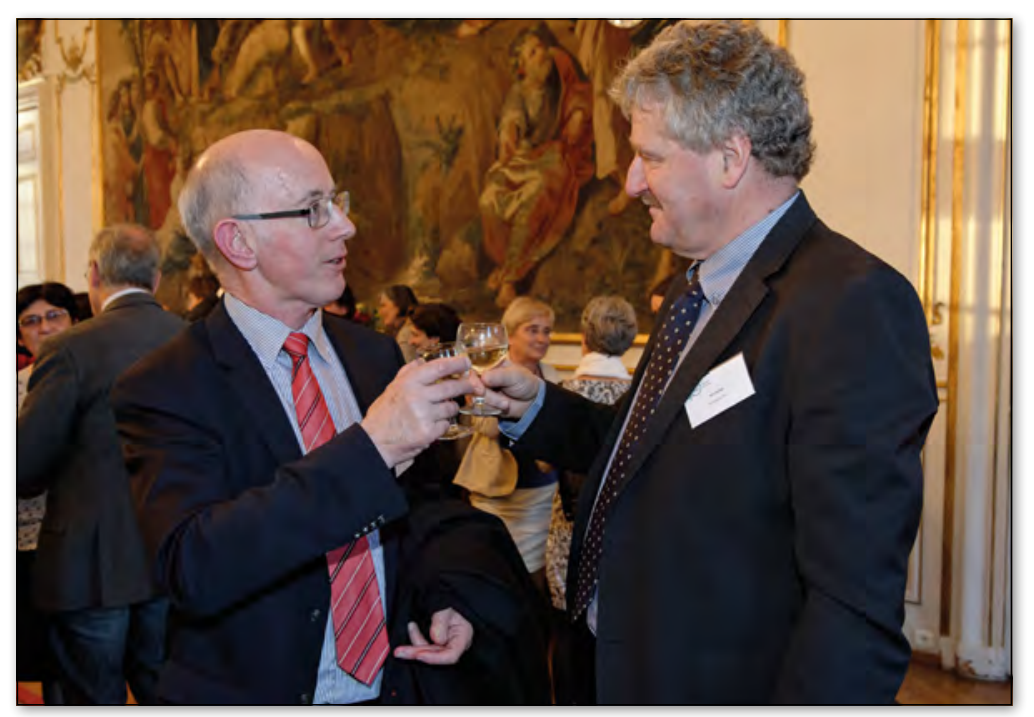

\section{A new trajectory}

A number of strategies for a new mission for ESF have been assessed. At the 2014 Assembly, the members agreed to allow business planning to proceed with a go/no-go deadline of end May 2015. If the business planning is accepted at that time, the existing association will not be dissolved.

With a new approach to working as a service provider rather than a wholly member-funded organisation, ESF is supporting the future of a globally competitive European Research Area by concentrating on activities designed to support and sustain the funding and conduct of scientific research across Europe. The aim remains to promote scientific developments through collaborative actions, but with the emphasis shifting to helping research funding organisations carry out their decision making processes. It is probable that members will decide to change the name and trading style.

The essential core of evidence-based support to scientific decision making will centre on: Peer Review [3], Evaluation [4], Expert Hosting, and Project Management.

\section{Peer Review}

ESF's European Peer Review Guide [5] (2011), issued on behalf of its members, and created from an in-depth analysis of peer review processes implemented by the leading European public research funding organisations, gave rise to considerable interest in good practice in this activity. ESF has been requested to carry out project work for many Member Organisations as well as other not-for-profit organisations. The work with the AXA Research Fund has proved particularly fruitful in delivering effective views of scientific excellence and in expanding the capabilities of both organisations. Further examples are listed on the ESF website at www.esf.org/serving-science/peer-review/ experience-and-references.html.

\section{Evaluation}

Similarly, evaluation services spring from a long-term dialogue with members on appropriate structures and methodologies. In 2012, ESF conducted a detailed review of scientific evaluation practices across European research organisations and issued a Member Organisation Forum report entitled Evaluation in Research and Research Funding Organisations: European Practices [6]. Recent projects include organisational evaluation and reports on the Research Council of Lithuania [7] and the Hungarian Scientific Research Fund (OTKA) [8].

\section{Specialised approach and practice}

ESF can provide expert reviews for specific competitive calls or full-scale call management, covering all aspects including planning and coordination of specialised peer 


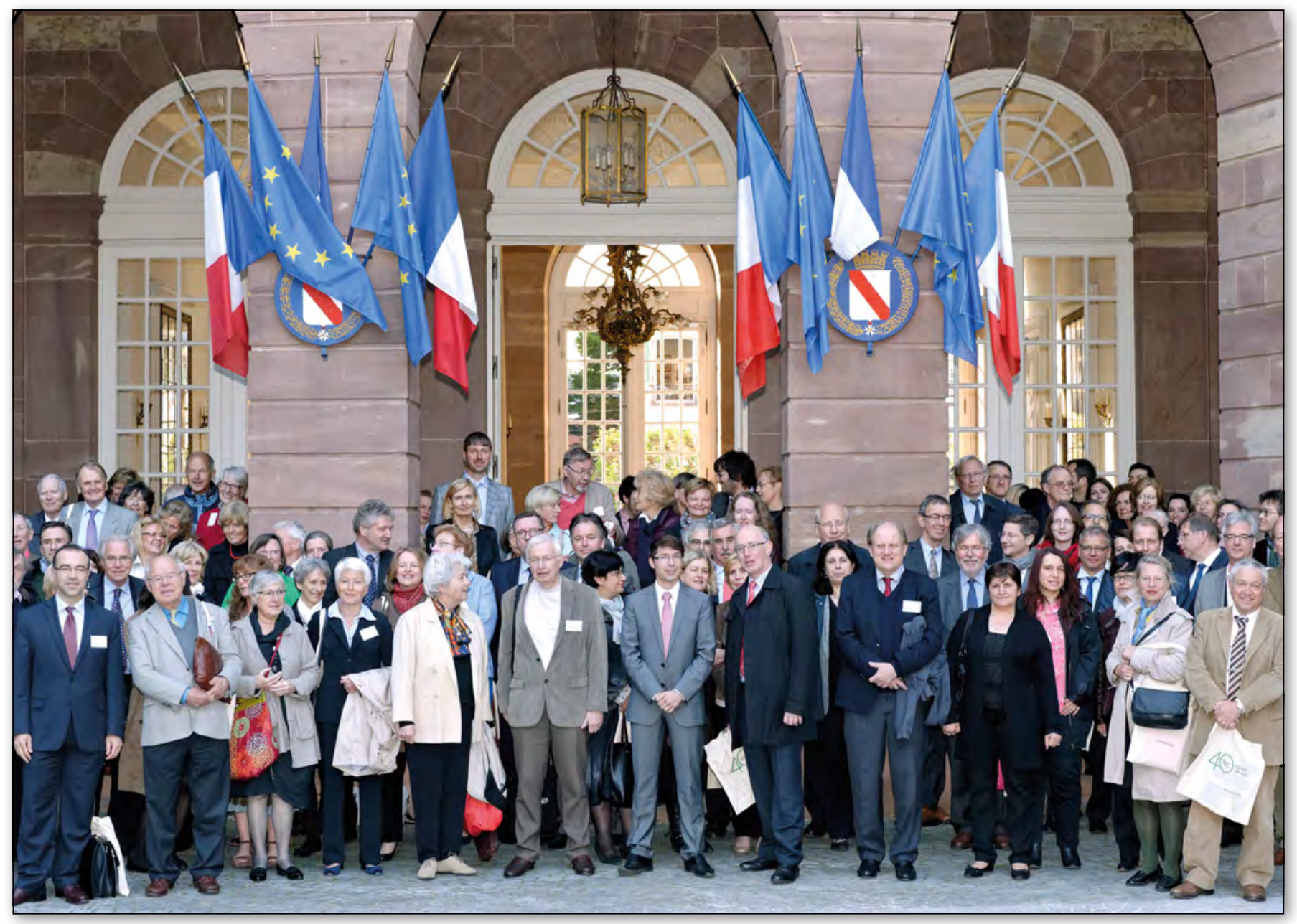

review and research evaluation assignments. With its highly regarded and experienced reviewers, ESF is able to provide outstanding scientific peer review support to institutes or organisations implementing competitive calls across all scientific domains. The process ensures that research proposals and applications are assessed for scientific quality, validity, significance and originality. The collective achievements of a funding programme can subsequently be evaluated to assess the overall effectiveness, outcomes and impact of the programme, while identifying improvements or policy implications for the future.

ESF is positioned as a benchmark peer review and evaluation provider at the European and international level.

\section{Expert Hosting}

For many years, ESF has hosted Expert Boards and Committees [9] with strong knowledge and experience of influencing ministerial and other high-level forums at the European and international level. These boards and committees have the expertise and authority to wield influence with decision makers and funding agencies. The Expert Boards and Committees develop the strategic approach to their domains in close collaboration with national authorities in member nations or European-wide agencies and research entities. They are composed of high-level independent researchers or research managers, nominated by their stakeholders to provide targeted expert advice in areas of science, policy, infrastructure, environment and society in Europe.

The 2011 Statutory Review of the Expert Boards and Committees [10], chaired by Professor Martin C.E. Huber, made a number of important recommendations regarding the future of these bodies - concluding "that all Boards and Committees provide scientific services in the European or even global framework that are indispensable for Europe's scientific landscape". The report observed on the possible hosting in future under the aegis of Science Europe.

Following further review and discussion, Science Europe concurred that the Boards and Committees were of value within their domains and that there was potential benefit to collaborating with these interdisciplinary groups. However, it felt that Science Europe would not be the appropriate platform from which to operate. For the successor to ESF, the maintenance of this platform and collaboration is of central importance. $\triangle$ FIG. 2: ESF's $40^{\text {th }}$ anniversary celebrations. 


\section{Project Management}

ESF can call on unrivalled experience managing both individual research projects and larger programmes at the international level. ESF has managed a considerable number of scientific projects funded by the European Commission and Member Organisations, supporting and collaborating with national institutions.

The COST Programme (European Cooperation in Science and Technology) was the largest at $€ 250$ Million during the duration of Framework Programme 7. In the frame of the ESF disengagement from the management of COST activities, a new legal entity, the COST Association, has now contracted with the EC under the new H2020 Framework Programme.

Having designed and implemented numerous collaborative programmes, including the Research Networking Programmes (RNPs) and EUROCORES (EUROpean COllaborative RESearch) scheme, ESF has enabled research teams in different European countries to collaborate in areas where European-wide scale and scope with cross-border cooperation were essential. Another example is its coordinator role in the FET Flagship project, Graphene.

An example of providing key support for European decision making is the MERIL [11] project, initially supported with Commission funding but now being advanced with members' support. The Mapping of the European Research Infrastructure Landscape project is an online database of research infrastructures across all fields of research in Europe. The resulting web portal gives an easily searchable list of openly accessible research infrastructures in Europe that are of more than national relevance across all scientific domains: http://portal.meril.eu/ converis-esf/publicweb/startpage?lang=1

ESF has particular expertise in the management of large, complex scientific programmes spanning different European countries and systems.

v FIG. 3: The annual contributions from ESF Members in k€. Note a reduction of 15.4 Million $€$ in 2015 compared to 2010. EUROCORES is the EUROpean COllaborative RESearch scheme, and RNPs are the ESF Research Networking Programmes described at: http://www.esf.org/coordinating-research/ research-networking-programmes.html

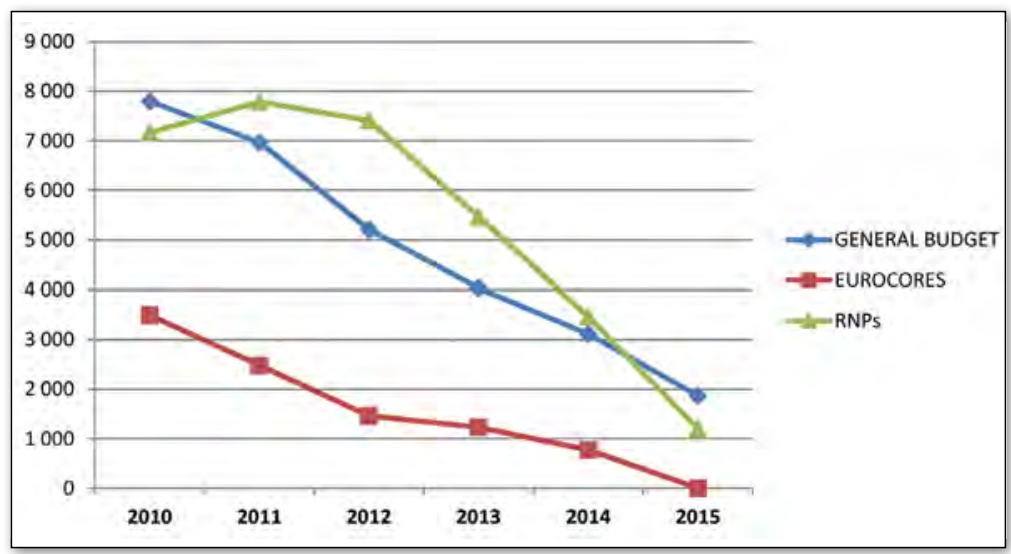

\section{Membership}

The November 2014 Assembly adopted amendments to the ESF statute that facilitate new types of membership in the organisation. Members can decide between taking part in the management and administration of the organisation, with voting rights and related responsibilities, or taking on a purely advisory role.

Full members are required to pay an annual contribution and, as a result, have access to ESF services at a preferential rate. Associate members are able to donate expertise and referees to help smaller countries develop their research programmes and smart specialist areas, thus assisting the development of science in the European Union..

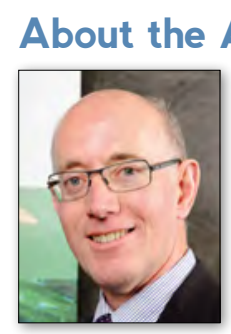

Author

Martin Hynes qualified as an Engineer. He commenced his career with the Westinghouse Electronics and Controls Company, followed by 10 years at the National Metrology service and new NML facilities in Ireland. He devoted the past two decades to research policy and research support systems, i.a. as Director of the Irish Research Council for Science, Engineering and Technology,IRCSET. His work in promoting French / Irish research collaboration was acknowledged by the award of the Chevalier des Palmes Académiques. He also received an award from the President of Ireland for excellence in research support. He was appointed Chief Executive of ESF in November 2011. He is a Chartered Engineer and Fellow of the Institution of Engineers, and completed an MBA at University College Dublin.

\section{References}

[1] http://40years.esf.org/

[2] www.scienceeurope.org/scientific-committees/ the-scientific-committees/

[3] www.esf.org/fileadmin/Public_documents/Publications/ peer_review.pdf

[4] www.esf.org/fileadmin/Public_documents/Publications/ evaluation.pdf

[5] www.esf.org/fileadmin/Public_documents/Publications/ European_Peer_Review_Guide_01.pdf

[6] www.esf.org/fileadmin/Public_documents/Publications/ mof_evaluation.pdf

[7] www.esf.org/fileadmin/Public_documents/Publications/ $\mathrm{RCL}$ _evaluation.pdf

[8] www.esf.org/fileadmin/Public_documents/Publications/ otka_evaluation_01.pdf

[9] www.esf.org/hosting-experts/expert-boards-andcommittees.html

[10] www.esf.org/fileadmin/Public_documents/Publications/ StatutoryReviewExpBoComm.pdf

[11] www.esf.org/serving-science/ec-contracts-coordination/ meril-mapping-of-the-european-research-infrastructurelandscape.html 